PROCEEDINGS OF THE 5TH WFOT MEETING; 2016 NOV 18-20; MUMBAI, INDIA

\title{
Role of ozone disc nucleolysis in herniated intervertebral disc: The indian experience
}

\section{Sharad Ghatge}

MBBS, DMRD, DNB Radiology, Consultant interventional Neuroradiologist and Interventional Ozone therapist. India.

\section{ABSTRACT}

OOPEN ACCESS

\section{Citation}

Ghatge S. Role of ozone disc nucleolysis in herniated intervertebral Disc: The Indian experience [abstract]. Proceedings of the 5Th WFOT Meeting; 2016 Nov 18-20; Mumbai, India. J Ozone Ther. 2018;2(2). doi: 10.7203/jo3t.

2.2.2018.11152

\section{Academic Editor}

Jose Baeza-Noci, School of Medicine, Valencia University, SPAIN

\section{Editor}

World Federation of Ozone Therapy, Bolgna, ITALY

\section{Received}

December 9, 2017

\section{Accepted}

December 10, 2017

\section{Published}

March 4, 2018

\section{Intellectual Property}

Sharad Ghatge. This is an open access article distributed under the terms of the Creative Commons Attribution License (CC BY 4.0), which permits unrestricted use, distribution, and reproduction in any medium, provided the original author and source are credited.

\section{Author Information}

drsharadghatge@yahoo.com

\section{AlM}

To study the role of ozone disc nucleolysis in herniated intervertebral disc.

\section{MATERIALS}

We retrospectively analysed consecutives patients undergoing ozone disc nucleolysis. There were a total of 5265 patients with 2740 males and 2525 females. Their age was ranging from 17 years to 84 years. Patients weight was ranging from 36 to 138 kilograms. All the patients had failed conservative management for at least 3 weeks.

\section{METHODS}

All the patients were clinically evaluated as per inclusion and exclusion criterions. Pre-treatment Visual Analogue scale (VAS) and Oswestry Disability Index (ODI). All the patients undergone Pre-treatments work up of MRI of the spine. 256 patients were undergone Nerve physiological study (EMG,NCV and SSEP). All the procedures were carried out in Cathlab (Siemen's Artis zee) under local anaesthesia.

In Lumbar region $3 \mathrm{cc}$ of ozone and in cervical $1 \mathrm{cc}$ of ozone-oxygen mixture injected. In Lumbar region additionally $7 \mathrm{cc}$ of ozone-oxygen mixture along with local anaesthetic (Lidocaine) - corticosteroid (Hydrocortisone and triamcinolone) - rheological enzyme (hynidase) injected in epidural space.

There were 4406 patients with Lumbar disc herniation and 861 patients with cervical disc herniation.

Statistical Analysis was done by SAS online version 2.

\section{RESULTS}

Outcome was assessed by VAS score, Oswestry Disability Index and modified MacNab scale at 6 month, 12 months and 18 months. The mean baseline VAS score was 9 which became 4.9 post ozone disc nucleolysis. Disability Index was 36.13 at baseline which improved to 9.86 post treatment. Success rate was $81 \%$ by Modified MacNab outcome scale. Results by all above mentioned the three methods were found to be statistically significant. 


\section{CONCLUSION}

Ozone disc nucleolysis is highly effective in the treatment of herniated intervertebral disc. It is safe, Durable and cost effective in our series. Our results were slightly better than the published literature. However randomised control trial is recommended to further substantiate our results.

Keywords: Ozone Disc nucleolyisis ; Herniated intervertebral disc. 